EREM 76/4

Journal of Environmental Research, Engineering and Management

Vol. 76 / No. 4 / 2020

pp. 68-75

DOI 10.5755/j01.erem.76.4.25460
Remediation of Soil Containing Sludge Generated by Printed Circuit Board Production and Electroplating

\title{
Remediation of Soil Containing Sludge Generated by Printed Circuit Board Production and Electroplating
}

\section{Anatoliy Nester}

Khmelnytskyi National University, 11 Institutska St., Khmelnytskyi 29016, Ukraine

\author{
Larisa Tretyakova, Liudmyla Mitiuk*, Natalya Prakhovnik, Arkadii Husiev \\ National Technical University of Ukraine "Igor Sikorsky Kyiv Polytechnic Institute", \\ 37 Peremohy Avenue, Kyiv 03056, Ukraine
}

*Corresponding author: luda2010703@gmail.com

This paper examines the environmental conditions at the premises of printed circuit boards (PCBs) manufacturers, which have electroplating plants. It provides a brief overview of the key aspects of adverse environmental impacts of wastes generated by PCB manufacture and electroplating plants. The aim of this research was to improve the test method for evaluation of wastewater effect on the soil salinity at the premises of PCBs manufacturers. The object of research was the process of extraction and use of copper from wastewater generated by PCBs manufacture and electroplating. As an example, the process of sludge formation during PCBs etching has been reviewed. With the etching line capacity of $14 \mathrm{~m}^{2} / \mathrm{h}$, one-shift manufacturing process will result in the production of up to $2,500 \mathrm{~kg}$ of sludge monthly. For enterprises with capacities of 2,000-4,000 $\mathrm{m}^{2}$ circuits, this means annual accumulation at their premises of up to 70 tons of wastes in the form of sludge. Estimates suggest that the upper half-meter layer of the aeration zone will be qualified as slightly saline in one year after accumulation of the sludge. In subsequent years, the salt content will increase and saline soil can be found at the depths of 1.5-2 $\mathrm{m}$ over ten years of storage. The authors of this paper propose to treat spent etching solutions applying regeneration technology in order to reduce the amount of sludge. With this technology, it is possible to use the extracted metal as a secondary raw material for copper production and re-use the regenerated solution in PCBs etching. This paper provides estimated hazard indices calculated for the storage of sludge at the manufacturer's premises before and after the implementation of the proposed technology. With regards to findings of the study, it has been proposed to reuse copper recovered from wastes as a raw material for the industry.

Keywords: production of printed circuit boards, regeneration, etching solutions, environmental hazard, sludge. 


\section{Introduction}

It is common knowledge that modern development of society depends on the resolution of the issue of minimizing industrial wastes and fulfillment of environmental safety requirements. According to the Law of Ukraine "On Environmental Protection", the environment is considered to be safe when its conditions meet the statutory prescribed criteria, standards and norms. Approved requirements, which determine the qualitative and quantitative levels of pollution and resource content, ensure the compliance with sanitary standards for the occupancy of specific groups of people.

Currently, the problem of industrial and domestic wastes disposal is becoming increasingly pressing as the amounts of wastes are constantly growing and their recycling rates are far below the required level. As a result, hundreds of millions of tons of solid and liquid wastes have been accumulated to date, which must be processed, rendered harmless, and stored (National report, 2017). The amounts of solid wastes generated and accumulated annually require the development and industrial implementation of powerful waste treatment plants capable of processing millions of tons of wastes per year (Nester, 2016). The problem is that bringing proposals to practical application in the industry is associated with financial, social and technical difficulties.

Currently, the most commonly used method of neutralizing toxic wastes is their disposal at special landfills lined with layers of clay, polyethylene, polyvinyl chloride and other waterproof materials. Landfills are harmful to the environment. Wastes containing unstable chemical elements pose an increased risk to people, animals and plants. They can pollute the air and also migrate into groundwater in the form of various compounds. As a result, harmful substances are absorbed by plants and get into food sources of animals and people. Chemical fixation is an effective measure for the disposal of liquid and solid wastes. It is performed by the addition of special reagents (sodium silicate, cement) to immobilize toxic substances in a solid-like structures. However, these substances may be washed-out over time. Modern technology makes it possible to utilize most of the waste, and use it as raw material in other industries.

Wastes containing metal salts are considered particularly hazardous, including galvanic sludge, which belongs to toxic wastes. The hazard degree of sludge depends on the technology applied in the galvanic process and technology used in wastewaters treatment. Depending on the characteristics of galvanic process (galvanizing line, nickel plating, chromium plating), the composition of the sludge changes. Galvanic sludge may contain various heavy metal compounds: chromium, manganese, iron, cobalt, nickel, copper, zinc, lead, cadmium, chromium, and mercury. It has been established that soil and water become contaminated with these heavy metal compounds in the manufacture of PCBs and electroplating. These industries contribute to the formation of liquid waste with metal content during etching and solid waste (sludge) during disposal. Storage of such wastes at the premises of manufacturers inevitably leads to long-term and difficult to recover environmental pollution. The levels of water pollution in Ukraine are very significant in the regions with galvanic and painting shops, since these are the top high-hazard processes, which cause toxic environmental pollution. In Ukraine, these processes are typically used in mechanical and electronic engineering industry and at the enterprises of the military-industrial complex. Enterprises that use PCBs manufacturing processes to ensure the operation of modern electronic equipment contribute to environmental degradation.

It has been established that copper compounds have mutagenic properties. Copper toxicity may cause liver and lung damage, hypertension, allergies and nervous system disorders. Cases of acute poisoning of people have been reported with drinking water that contained $0.14 \mathrm{mg} / \mathrm{kg}$ or more copper (Filov, 1988). Copper is extremely dangerous for the majority of freshwater invertebrates and causes their death at a concentration of $0.01 \mathrm{mg} / \mathrm{dm}^{3}$. The maximum permissible concentrations (MPCs) for copper in drinking water are the following: $0.052 \mathrm{mg} / \mathrm{dm}^{3}$ according to the European standards; $1.0 \mathrm{mg} / \mathrm{m}^{3}$ according to the USA standards, and $2.0 \mathrm{mg} / \mathrm{dm}^{3}$ according to WHO recommendations. For fisheries, the maximum permissible concentration of copper shall not exceed $0.01 \mathrm{mg} / \mathrm{dm}^{3}$.

Ukraine has high demand for copper, which is widely used in the electrotechnical, aircraft and electronic industries. Open pit mining is the most common way of metallic ores (including copper) extraction. This technology is used to extract more than $70 \%$ of all minerals in the 
world. This is a relatively cheap method of mining that allows using powerful and highly productive equipment. However, long-term open-casting is associated with withdrawal of huge areas of agricultural and forest lands from economic circulation. To access the deposit, it is necessary to excavate, move and dispose of waste rock, the volumes of which exceed several times the volumes of extracted minerals (Chervonyy et al., 2014).

The second most important method of developing deposits is underground mining. In this way, up to $20 \%$ of iron, $45 \%$ of copper, $70 \%$ of zinc, $75 \%$ of tin and lead, and $100 \%$ of tungsten are extracted. The costs of underground ore mining are higher than those of open pit mining. This technique is used for deposits where open mining is economically impractical or technically impossible. Due to the gradual depletion of readily available reserves of metal ores, the depth of mining is constantly increasing, which is a global tendency today. In Canada, the extraction of ores that contain gold, copper, and nickel is carried out at depths of 1,800-2,600 m. In the USA, copper and gold are mined at depths of 1,700-3,000 $\mathrm{m}$. The world's deepest-seated deposit is under development in the South African Republic: the work is carried out at a depth of more than 4,000 $\mathrm{m}$. Underground mining makes it possible to completely preserve the earth's surface, which is beneficial for the conservation of the natural environment (Chervonyy et al., 2014).

There are no explored copper-ore deposits in Ukraine. Prospective and predicted resources of copper ores were identified in the Donbass region, Dnieper-Donets basin, Middle Dnieper and Volyn regions. The estimated total ore resources of Volyn region with an average copper content of $1.0 \%$ are 28 million tons. As seen from the above, Ukraine lacks copper ore deposits. The annual requirement of Ukraine of this metal is approximately 120-140 thousand tons. Twenty percent of the required amount are covered by available copper scrap, and the remaining volumes are imported from Russia and Poland as blister copper (Chervonyy et al., 2014).

The complexity and acuteness of the problem lie in the fact that Ukrainian consumers, who urgently need copper, are forced to purchase significant amounts abroad. At the same time, the capacities for the production of rolled copper and its alloys available in Ukraine are not utilized due to the absence of copper raw materials. A significant share of copper containing scrap is exported for various reasons, although it is obvious that the export of rolled copper and its alloys is much more efficient than the export of scrap and copper wastes. Each ton of exported tolled copper, in addition to maintaining jobs, may generate additionally up to USD 1,000 of currency earnings, which is $30-40$ million US dollar annually. Therefore, recovery of copper from printed circuit board industry wastewater is a matter of significant importance.

As seen from the analysis of literature, treatment and re-use of such wastes has got little attention recently. There are few theoretical papers available only, which deal specifically with a drilling sludge (Melnik, 2011). This lack of systemic research may be due to the unavailability of effective methods for assessment of pollution levels and techniques for extraction and recycling of metals from liquid and industrial wastes.

The purpose of this paper is to improve the method for assessing the impact of wastewater on the salinity of soil at the premises of printed circuit boards manufacturers. The subject of research is the process of recovery and use of copper from wastewater generated by PCBs manufacture and electroplating.

\section{Materials and Methods}

\section{Sample collection and preparation}

Copper is widely used in the production of printed circuit boards (PCBs) and galvanic processes due its high electrical conductivity. The process of copper etching requires large amounts of running water, and as a result, leads to accumulation of large amounts of copper in wastewater. Therefore, this process may be regarded the main anthropogenic source of copper in the environment. Analysis of stored wastes from PCBs production and electroplating has shown that they contain large amounts of numerous metals (Pashayan and Karmanov, 2018). Due to high water content, looseness and permeability of soil, it is rather difficult in Ukraine to choose proper territories for industrial waste disposal, and such territories are limited. Exposed to precipitation, especially acid rains, solid wastes turn into liquid ones. This process creates the conditions for a gradual 
secondary pollution of soil. As a result, heavy metal pollution is found not only in topsoil adjacent to waste disposal sites and surface water, but also in underground water tables (Nester and Rogov, 2015).

The authors studied experimentally the process of sludge accumulation during operation of etching lines in printed circuit boards production on the example of electronic equipment manufacturer. Average production capacity of the enterprise is approximately 2,500 $\mathrm{m} 2$ of boards per month. With an etching line capacity of $14 \mathrm{~m} 2 / \mathrm{h}$, the amount of generated sludge will reach $100-120 \mathrm{~kg}$ in 8 hours of operation. One month of single-shift operation will result in $2,400-2,500 \mathrm{~kg}$ of sludge, and two-shift operation will generate around $5,000 \mathrm{~kg}$ of sludge. The survey showed that enterprises engaged in the manufacture of printed circuit boards discharge a wide range of metals: copper, iron, nickel, and chromium.

Up to 70 tons of wastes are accumulated annually in the form of sludge at the premises of manufacturers with capacities ranging from 2,000 to $4,000 \mathrm{~m}^{2}$ of boards. Sludge is stored in plastic bags, which can be exposed to atmospheric precipitation. As a result of storage of salts generated during PCBs etching and electroplating, the soil salinity increases. When exposed to atmospheric precipitation, salts become washed out and migrate into soil and surface layers of water causing environmental pollution.

Uncontrolled discharge of spent etching solutions into the natural environment can cause the following adverse effects:
1 chemical pollution of the environment (air, water, soil);

2 increased morbidity rates, especially among younger people, including potentially fatal cases;

3 damage to industrial and residential buildings.

According to the analysis of chip production waste, the percentage of a number of metals was determined (Table 1).

The enterprise, with productivity ranging from 2,000 to $4,000 \mathrm{~m}^{2}$ of chips, accumulates from 30 to 48 tons of waste annually. In previous years, the sludge was stored on the territory of the enterprise in landfills in open areas. For the last 20 years, the sludge has been stored in polyvinylchloride packages.

All soils contain certain amounts of salt. The soil salinity is measured as proportion in dry soil. For clarity, let us determine the values of salinity: soils containing less than $0.3 \%$ of salts from PCBs etching and electroplating are considered non-saline, and soils with the content of salts about $0.3-0.5 \%$ are considered slightly saline.

\section{Simulation of the soil contamination process in the sludge storage area}

Below is the proposed method for predicting soil contamination at sludge storage sites. The movement of salts from the earth surface to the lower layers of an aeration zone is guided by the molecular diffusion mechanism (Fig. 1). Soils in the area have the following structure: loam $-h_{1} \leq 1.5 \mathrm{~m}$; sand $-h_{2} \leq 0.3 \mathrm{~m}$; groundwater $-h_{3} \leq$ $0.8 \mathrm{~m}$; clay $-h_{4} \leq 1.2 \mathrm{~m}$; then the interlayer water begins. The pores are up to $40 \%$ of the volume of the soil layer.

Table 1. Content of Metals in the Test Samples of Sludge

\begin{tabular}{l|c|c|c|c|c|c}
\multicolumn{1}{c|}{ Indicators } & \multicolumn{5}{c}{ Metal content in industrial sludge } \\
\hline Type of metal & Copper & Calcium & Iron & Chromium & Nickel & Zinc \\
\hline Metal content, \% wet soil & 16 & 8 & 9 & 2 & 3 \\
\hline Harm class & 3 & 4 & 3 & 3 & 3 \\
\hline $\begin{array}{l}\text { Limit concentration in } \\
\text { water, mg/dm }\end{array}$ & 1.0 & 3.5 & $0.3^{3}$ & 0.05 & $0.1^{3}$ & 1.0 \\
\hline
\end{tabular}


Fig. 1. Schematic representation of a soil layer with penetrating copper salts

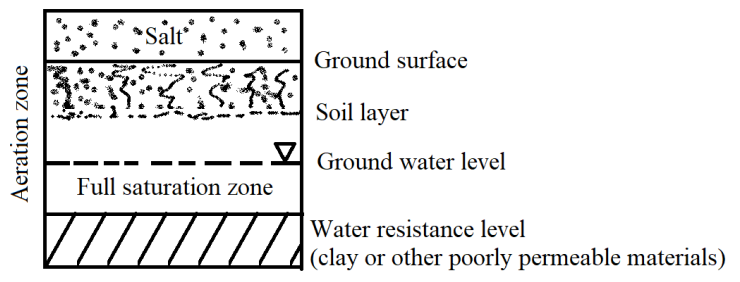

According to physicochemical fluid dynamics in porous media, the process of metal salts motion can be described by the partial differential equation of motion and conservation of substance mass for vertical mass transfer (Evgrashkina and Kalinkina, 2015). The presence of salt on the surface of soil corresponds to the first-type boundary condition.

$$
D_{m} \frac{d^{2} C}{d x^{2}}=n \frac{d C}{d t}
$$

Where: $D_{m}$ - maximum molecular diffusion coefficient, $\mathrm{m}^{2} /$ day; $C$ - salinity of soils, \% density of dry soil; $n$ degree of moisture content, unit fraction; $X$ - spatial coordinate, $\mathrm{m} ; \mathrm{T}$ - time coordinate, days.

The analytical solution of equation (1) for the problem in this formulation:

$$
C x=(C n-C o) \operatorname{erfc} \frac{x}{2 \sqrt{\frac{D_{m} t}{n}}} .
$$

Where: $C x$ - predicted salinity at a depth $x$ from the earth's surface, \%; $\mathrm{Cn}$ - salinity on the surface (bulk layer of salts), \%; Co - salinity of the soil before storage, $\% ; x$ - distance from the calculated points to the origin, i.e. from the earth's surface, $\mathrm{m}$; $t$ - period of predicted calculation, days; erfc - tabulated exponential function.

In the course of prediction, the following assumptions are made: the process of accumulation of metals is cumulative; annual seasons of soil moisture change are not taken into account. One year ( 365 days) is accepted for the billing period. The total prediction time is 20 years.

\section{Results and Discussion}

For the estimated overall level of pollution, a reference point at a distance of $0.5 \mathrm{~m}$ from the surface was selected. To predict pollution at the premises of the enterprise, the following initial data were used: soil salinity at the beginning of storage $-\mathrm{Co}=0.2 \%$; maximum value was the molecular diffusion coefficient $D_{m}=$ (1) $\cdot 10^{-5} \mathrm{~m}^{2} /$ pore; volumetric humidity $n=0.23$. The period of predicted calculation was one year (365 days). The movement of salts occurs in the pore space only. The maximum value of salinity on the surface will be max $\left(C_{n}\right)=100 \%$.

The molecular diffusion coefficient $D$ characterizes the movement of metal ions as a result of thermal motion in the soil and depends on the properties of metal molecules, temperature and pressure. In the calculations, the reference value $\mathrm{D}$ was taken at a temperature of $20^{\circ} \mathrm{C}$

Substituting the selected values in the formula (2), we obtain the following value:

$$
(100-0.2) \operatorname{erfc} \frac{0.5}{2 \cdot \sqrt{\frac{1 \cdot 10^{-5} \cdot 1 \cdot 365}{0.23}}}=
$$

$=99.8 \cdot \operatorname{erfc} 1.98=99.8 \cdot 0.005=0.499$.

The results of changing the depth of penetration of metals into soil layers by years are shown (Fig. 2).

According to the graphs (Fig. 2), the storage of sludge in open areas annually results in the increase in the depth of soil salinity.

The calculation results showed that in case of open storage of sludge, a $0.5 \mathrm{~m}$ layer of upper aeration zone will become slightly saline in one year. In subsequent years, the salt content will increase in depth over time. After 15-20 years, the salt profile will reach a depth of $1.5-2 \mathrm{~m}$, which will pose a serious threat to the underlying groundwater.

\section{Assessment of the feasibility of recycling galvanic production waste}

Currently, Ukraine reuses nearly a quarter of all generated chemical wastes. Many countries of the world have experience of recovery of metals from the wastes, including wastes generated in PCBs production and electroplating. 
Fig. 2. The level of soil salinity at the depth of penetration during storage of sludge in the open area: 1 - one-year storage; 2 - five years; 3 ten years; 4 - twenty years.

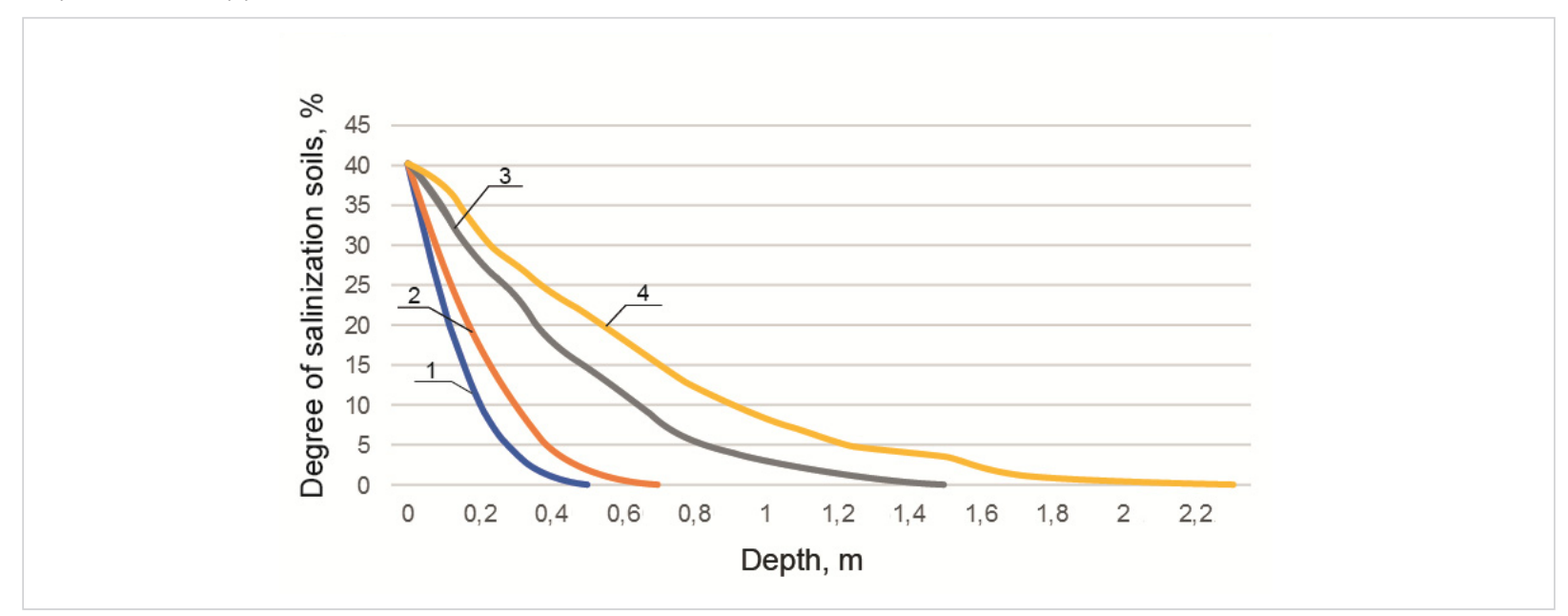

For example, in Germany, the re-use of iron reaches up to $38 \%$, the re-use of tin is $34 \%$ and that of zinc is $33 \%$; in the USA, $43 \%$ of copper is reused, and in the UK, $60 \%$ and $33 \%$ of lead and aluminum are re-used, respectively (Nester, 2016). The proportion of secondary raw materials in the production of non-ferrous metals in Ukraine is constantly growing. In the future, secondary raw materials should become the main source of many non-ferrous metals, in particular copper. Utilization of secondary raw materials in the metallurgical production cycle is of great economic importance, since it allows to use non-renewable natural resources efficiently, reduce the environmental impact and produce metals in simpler and cheaper ways. Studies indicate that copper recovered from wastewater meets established requirements and may be further used for melting or metallization of substrates in the corresponding technological processes (Vershinina and Martynenko, 2019). It should be noted, however, that recovery of metals from wastes is economically feasible in cases where their concentrations are high enough and the technologies used are not energy-consuming. The specifics of their content in electroplating wastes as well as identification of their chemical properties and characteristics should be considered. These factors are essential for the development of special technologies that take into account the features of special chemical recovery methods.

Electroplating involves sequential electrochemical processes resulting in the formation of liquid soluble and solid insoluble precipitates. Electrolytes of various purpose and etching solutions may pass into wastewater. At sewage treatment plants, sludge from etching and electroplating is formed in non-dehydrated and dehydrated forms. Thus, there is a significant amount of waste that needs to be disposed of. This requires two different technologies: utilization of etching solutions and processing of sludge. The difficulty with the disposal of galvanic waste is that the waste is divided into several categories, depending on the used recycling technologies (Prolejchik et al., 2018).

In order to improve environmental security during sludge storage and produce additional amounts of copper, it is proposed to use the technology of regeneration of spent etching solutions. Metal recovered in this process may be utilized as a secondary raw material for the production of copper, and regenerated solution may be reused in the etching of printed circuit boards. The regeneration of spent solutions is carried out in a regeneration unit, with elements, technological process, composition and parameters of solutions described in (Nester, 2016).

When assessing the environmental hazard associated with the sludge generated by PCBs production and electroplating, the following should be taken into account: the degree of chemicals penetration into surface and underground water, and their accumulation in soil and plants, which is measured according to solubility of chemical compounds in water. Waste toxicity is characterized by the Maximum Permissible Concentrations (MPCs) of substances in the soil and their content in the total mass 
of sludge (Dorokhina and Kharchenko, 2017). The hazard index for each chemical agent is calculated by the following formula:

$$
K_{i}=\frac{M P C_{i}}{\left(S+C_{6}\right)_{i}}
$$

Where: $K$ - hazard index; MPC - maximum permissible soil concentration of hazardous chemical agent contained in waste, $\mathrm{mg} / \mathrm{kg}$; $S$ - coefficient of chemical agent solubility in water; $C_{B}$ - content of chemical agent per total mass of waste, $\mathrm{mg} / \mathrm{kg} ; i$ - number of studied substance.

The total sludge hazard index calculated prior to recovery of copper at the selected enterprise in Ukraine is given below (Table 2)

Table 2. Calculated Sludge Hazard Index

\begin{tabular}{|c|c|c|c|}
\hline Group of substances & $M P C_{i}, \mathrm{mg} / \mathrm{kg}$ & $\left(S+C_{B}\right)_{i}, \mathrm{mg} / \mathrm{kg}$ & $K_{i}$ \\
\hline \multirow{2}{*}{ Copper compounds } & \multirow{2}{*}{3} & 73.98 & 0.0405 \\
\hline & & 21.15 & 0.141 \\
\hline
\end{tabular}

Following recovery of copper compounds from wastewater (not turned into sludge), the total hazard quotient falls significantly and such wastewater can be considered to have negligible hazard (Table 3).

Table 3. Hazard Index Calculated for Sludge after Recovery of Copper

\begin{tabular}{l|c|c|c}
\hline Group of substances & $M P C_{i}, \mathrm{mg} / \mathrm{kg}$ & $\left(\mathrm{S}+\mathrm{C}()_{i}, \mathrm{mg} / \mathrm{kg}\right.$ & $K_{i}$ \\
\hline \multirow{2}{*}{ Copper compounds } & 3 & 0.01 & 300.0 \\
\cline { 3 - 4 } & & 0.03 & 100.0 \\
\hline
\end{tabular}

The data presented point at the need to develop closed cycles and integrated solutions for the use of water, solutions and recovered metals, avoiding their accumulation at the premises of manufacturers.

The economic efficiency of wastes recycling for the studied type of enterprises can be estimated in the following way. During the annual one-shift operation of the etching line of printed circuit boards with a capacity of $14 \mathrm{~m}^{2}$ per hour, up to $28,000 \mathrm{~m}^{2}$ of billets will be produced, and the amount of metal (copper) extracted will be up to 14 tons. At the current price of \$ 3.4 per kilogram, the additional cost obtained will be $\$ 47,600$. With the full use of 350 lines installed at the enterprise, the amount of copper can increase to 4,900 tons per year. This metal can be reused in accordance with the recommendations that are proposed in this paper.

According to our results, the upper half-meter layer of the aeration zone will fall into the category of slightly saline soils in one year of sludge storage. In subsequent years, the salt content will increase and after 10 years the saline soils may reach the depths of 1.5-2 $\mathrm{m}$. These concentrations of salt in the soil mean that it is absolutely unfit for life, and there will be no living organisms or plants for many years, even after liquidation of a warehouse at the premises of the enterprise.

The resolution of the issue of improving the environmental security at the enterprises, on the premises of which the wastes generated by PCB manufacture and electroplating are stored, requires an integrated approach and implementation of preventive and remedial measures. Firstly, this includes technological and managerial actions aimed at prevention of environmental pollution through the use of ecologically safe reagents and solutions, which allow reducing wastes toxicity. Technological processes used in the manufacture of PCBs and electroplating should include measures aimed at reducing the amount of wastes. Production wastes should undergo recycling. The methods of recycling are environmentally friendly and cost-effective, and with their application the sludge may turn into a source of building materials and agricultural fertilizers, and wastewater may be re-used in manufacturing processes.

\section{Conclusions}

This paper analyzed the characteristics of wastes generated by printed circuit boards production and electroplating, and their impact on the environment in Ukraine. It defined emergency situations that require a full range of measures to be taken for disposal of heavy metals.

The main result of this study is an improved method for assessing soil contamination caused by printed circuit boards and electroplating factories in Ukraine. The paper provides further insight into the hazards associated with the storage of sludge at the premises of manufacturing 
enterprises. This study also discussed the issues related to the development of technologies for processing and re-use of etching solutions. Summing up the results, it can be concluded that the technological solutions proposed in this paper will help to reduce the volumes of hazardous sludge stored at the premises of enterprises and improve the environmental situation in the future.

The findings of this research are of direct practical relevance; however, their implementation requires extensive outreach campaigns to be carried out at enterprises and educational institutions training specialists for respective industries. It is also necessary to raise public knowledge and awareness about the conditions and storage of wastes at the premises of enterprises, in particular PCBs manufacturers that have electroplating plants. Clearly, further research will be needed to develop technical solutions for sludge processing suitable for each individual enterprise (with due regard to the technological processes utilized by the enterprise), preventing the formation and long-term storage of wastes at their premises.

\section{References}

Chervonyy I., Bredikhin V., Gritsay V., Ignatev V., Ivaschenko V., Manyak M., Smirnov V. (2014). Kolorova metalurgiya Ukrainy: monografiya. Zaporizhzha, ZDIA. [Non-ferrous metallurgy of Ukraine: monograph]. 380 p.s. (in Ukrainean).

Dorokhina E., Kharchenko S. (2017) Ekonomika zamknutykh tsiklov: problem i puti razvitiya. [Circular Economy: Problems and Ways of Development]. Ekologiya i promyshlenost Rossii 21(3): 5055. (in Russian). Available at: https://doi.org/10.18412/1816-03952017-3. https://doi.org/10.18412/1816-0395-2017-3-50-55

Evgrashkina G., Kalinkina 0. (2015). Matematicheskie modeli izmeneniya gidrogeologicheskikh usloviy $v$ zone vliyaniya shakhtnogo vodootliva. [Mathematical models of changes in hydrogeological conditions in the mine drainage impact zone]. Visnyk Dnipropetrovskogo universytetu. Seriya: Geologiya. Geografiya. T 23, 17: 33-37. (in Russian). Available at: http:// nbuv.gov.ua/UJRN/vdugg_2015_23_17_6.

Melnik 0. (2011). Galvanycheskie shlamy est toksicheskie otxody ili vtorichnoe syre. [Galvanic sludge is toxic waste or secondary raw materials]. Visnyk Sumy National University 46: 185-189. (in Russian).

Natsionalna dopowid pro stan nawkolyshnogo pryrodnogo seredowyscha v Ukraini (2017). Kyiv, Ministry of Environment and Natural Resources. [National report on the state of the natural environment in Ukraine]. (in Ukrainian). Available at: https://mepr.gov.ua/news/31768.html

Nester A. (2016). Ochystka stichnykh vod vyrobnytsva drukovanykh plat: monografiya. Khmelnytsky, National Universi- ty Publishing House. [Sewage treatment from printed circuit board production: monograph]. 219 p.s. (in Ukrainian).

Nester A., Rogov V. (2015) Regeneratsiya stochnykh vod proizvodstva pechatnykh plat. [Wastewater recovery from printed circuit board production]. Vestnik Sankt-Peterburgskogo universiteta. Seriya 4. Fizika. Khimiya 2 (60): 72-79. (in Russian).

Pashayan A., Karmanov D. (2018). Utilizatsiya galvanicheskikh stokov bez obrazovaniya galvanoshlamov. [Recycling of Electroplating Wastes without Formation of Galvanic Sludges]. Ekologiya I promyshlenost Rossii. 22(12): 19-21. (in Russian). Available at: https://doi.org/10.18412/1816-0395-2018-12-19-21

Prolejchik A., Gaponenkov I., Fedorova O. (2018). Izvlechenie ionov tyazhelykh metalov iz neorganicheskikh stochnykh vod. [Extraction of Heavy Metal lons from Inorganic Wastewater]. Ekologiya I promyshlenost Rossii 22(3): 35-39. (in Russian). Available at: https://doi.org/10.18412/1816-0395-2018-3-35-39 Vershinina I., Martynenko T. (2019). Problemy uti lizacii otkhodov I socialno-ekologicheskoe neravenstvo. [Problems of Waste Recovery and Socio-Ecological Inequality]. Ekologiya i promyshlenost Rossii. 23(5): 52-55. (in Russian). Available at: https: https://doi.org/10.18412/1816-0395-2019-5-52-55

Vrednye khimicheskie veschestva. Neorganicheskie soedineniya elementov I - IV grup. Pod obschey redakciey V.A. Filova. (1988): spravochnik. Leningrad, "Khimiya”. [Harmful chemicals: Inorganic compounds of elements of groups I - IV: Handbook]. 512 p.s. (in Russian). 